\title{
SUPERIORITY OF ARTIFICIAL NEURAL NETWORKS OVER STATISTICAL METHODS IN PREDICTION OF THE OPTIMAL LENGTH OF ROCK BOLTS
}

\author{
Hadi Hasanzadehshooiili ${ }^{1}$, Ali Lakirouhani ${ }^{2}$, Jurgis Medzvieckas ${ }^{3}$ \\ ${ }^{1,2}$ Department of Civil Engineering, University of Zanjan, Zanjan, Iran \\ ${ }^{3}$ Faculty of Civil Engineering, Vilnius Gediminas Technical University, \\ Sauletekio al. 11, LT-10223 Vilnius, Lithuania \\ E-mails: ${ }^{1}$ h.hasanzadeh.shooiili@gmail.com; ${ }^{2}$ rou001@znu.ac.ir; \\ jurgism@vgtu.lt (corresponding author) \\ Received 25 Jan. 2012; accepted 17 Jul. 2012
}

\begin{abstract}
Rock bolting is one of the most important support systems used for rock structures. Rock bolts are widely used in underground excavations as they are suitable for a wide range of geological conditions and allow using progressive design methods; besides, they help economising in the use of materials and manpower. Thus, to provide the most effective support at minimum cost by means of rock bolting, it is essential to optimise the elements contributing to bolt design, including their length, as well as bolt density and tension during installation. This paper considers the length of bolts for optimisation of the design phase, which is one of the most important parameters impacting the entire design procedure. Presenting and comparing results of some statistical models, neural network modeling is introduced as powerful means in prediction of the optimal length of rock bolts. Subsequent to training and testing of a large number of 1-layer and 2-layer backpropagation neural networks, it was reported that the optimal model was the network with the architecture of 6-18-31 as it demonstrated the minimum RMSE and MAE as well as the maximum $\mathrm{R}^{2}$. In comparison to statistical models ( 0.7182 for the value of $\mathrm{R}^{2}$ in the multiple linear regression model, 0.68 in the polynomial model and 0.7 in the dimensionless model), the results obtained by the neural network modeling - i.e. the coefficient of determination $\mathrm{R}^{2}$ of 0.9259 , the value of mean absolute error MAE of 0.068 , and the root mean squared error RMSE of 0.078 - not only proved their superiority but also introduced the neural network modelling as a highly capable prediction tool in forecasting the optimal length of rock bolts. Furthermore, sensitivity analysis was used to obtain parameters that have the greatest and the least impact on the optimal bolt length: the effect of the overburden thickness, tensile strength, cohesion and Poisson's ratio on the optimal bolt length was almost the same while the friction angle had the least influence.
\end{abstract}

Keywords: optimal length of rock bolts, artificial neural networks, statistical methods, sensitivity analysis.

\section{Introduction}

Geotechnical and mining engineering cover a wide range of fields (Amšiejus et al. 2009; Žaržojus, Dundulis 2010; Zavadskas et al. 2010; Kelevišius et al. 2011; Hasanzadehshooiili et al. 2012; Sivilevičius et al. 2012). They are generally related to design and control of surface or subsurface structures. Furthermore, use of rock bolts in underground constructions has been one of the most popular support methods applied by geotechnical and mining engineers (Barton et al. 1974; Unal 1983; Chua et al. 1992; Cai et al. 2004a, b). As soon as the rock bolting method was developed in the 1920s, it was proposed as a systematic method for weak roof support by Weigel (1943). This method has numerous advantages in comparison to other methods. For instance, one of such advantages manifests through a more cost-efficient use of materials and manpower. Furthermore, this active support method is more effective and efficient as it utilises the rock to support itself by applying internal reinforcing stress. Besides, it can be used under different geological conditions (Barton et al. 1974; Luo 1999).
However, the variety of geological conditions is inexhaustible (Sušinskas et al. 2011). Actually, due to the complexity of geological conditions and mechanisms of bolting technology and since most decisions are made based on previous experiences, the design of rock bolts could be attributed to an art form rather than a science (Peng, Tang 1984; Luo 1999). In order to select a suitable bolting system, design parameters - such as the bolt length, bolt density and bolt pretension during installation - are usually considered to be optimal.

In this paper, the length of rock bolt, which is one of the most important design parameters, is considered to be optimal.

As a matter of fact, from a theoretical viewpoint, a bolted beam is as strong as a solid beam made out of the same material. Thus, finding the optimal length of a bolt is equivalent to finding the minimum solid beam thickness (Luo 1999). Besides, independent parameters that affect the strength of a solid beam include Young's modulus, Poisson's ratio, overburden thickness, cohesion, friction angle and tensile strength (Luo 1999). 
Thus, to produce a comprehensive study of the optimal length of rock bolts, professor Luo (1999) computed the minimum solid beam thickness during an experiment that involved random sampling of each of the independent variables for each of the data series.

Then, to efficiently and cost-effectively predict the optimal length of rock bolts, some statistical analyses such as multiple linear regression analysis, polynomial regression analysis, dimensionless analysis and the optimised statistical analysis - were undertaken (Luo 1999). Although numerous efforts have been made to predict the optimal bolt length, low value of the correlation coefficient obtained by statistical models reveals the urgent need for a substitute forecasting method.

Also, to select the optimal bolting system, the mathematical programming theory and methods can be applied. Such techniques have been used to solve a similar problem, i.e. optimisation of beams in grillage structures (Kim et al. 2005; Belevičius et al. 2002). Also, solving optimisation problems, promising results have been achieved with Genetic Algorithms (GA) (Belevičius, Šešok 2008). Global optimisation of grillages using simulated annealing and high performance computing is given in Šešok et al. (2010). Besides, the method of objectoriented programming (OOP) for optimal design of steel frame structures had been suggested by Jankovski, Atkočiūnas (2010).

As mentioned earlier, the ultimate goal for the bolt design paradigm, achieving a minimum solid beam thickness, is gained by optimising the bolt length, bolt density and bolt pretension during installation (Stankus, Guo 1997). Bolt binding effects are accomplished using three basic mechanisms: suspension, beam building and keying. In most situations, both suspension and beam building effects coexist. The keying effect mainly depends on active bolt tension. To determine the bolt length, pretension and spacing required for the optimal beaming effect, the abovementioned global optimisation methods can be used.

On the other hand, because of their multidisciplinary nature, artificial neural networks are commonly applied by the majority of researchers working in different branches of science (Goh et al. 1995; Maity, Saha 2004; Schabowicz, Hoła 2008; Baalousha, Celik 2011). Besides, high capabilities of this tool in prediction of complicated functions have been broadly proved (Abu Kiefa 1998; Malinowski et al. 2006; Malinowski, Ziembicki 2006; Mang et al. 2009; Dikmen, Sonmez 2011). Thus, to attain a rugged, cost-effective and timely prediction of the optimal bolt length, the applicability of ANNs has been investigated. For this purpose, using the data sets prepared by Luo (1999) and training numerous 1-layer and 2-layer backpropagation networks, several networks were created and for all the built networks, the value of the correlation coefficient, the root mean squared error, the mean absolute error and the fitting line's slope were calculated.

In order to show the superiority of the neural network modelling over other statistical methods, values of the correlation coefficient for all of the built models were presented and compared. Moreover, the sensitivity analy- sis was made using the cosine amplitude method to obtain parameters that have the greatest and the least impact on the optimal bolt length (Yang, Zhang 1997).

\section{Input and output parameters}

To gain the minimal thickness of a solid beam or the optimal length of a rock bolt, roof bolts used for an underground opening with a constant roof span amounting to 20 feet was considered (Luo 1999). Since parameters that impact on the strength of a solid beam primarily include Young's modulus, Poisson's ratio, overburden thickness, cohesion, friction angle and tensile strength, these six variables were considered as independent variables that impact on the optimal bolt length (Luo 1999). By means of a completely randomised design technique, each independent variable was sampled 50 times to construct a comprehensive database consisting of 50 groups of independent variables. Then, for each group, the minimal thickness of a solid beam was computed as an output parameter (Luo 1999). Ranges of variation of six independent sampled variables together with the corresponding values of the optimal bolt length are shown in Table 1 (Luo 1999).

Table 1. Input and output parameters (Luo 1999)

\begin{tabular}{c|l|c|c}
\hline $\begin{array}{c}\text { Type of } \\
\text { data }\end{array}$ & \multicolumn{1}{|c|}{ Parameter } & Symbol & Range \\
\hline \multirow{4}{*}{ Input } & Young's modulus $\left(\mathrm{Lb} / \mathrm{Inch}^{2}\right)$ & $\mathrm{E}$ & $\begin{array}{c}147941- \\
1160320\end{array}$ \\
\cline { 2 - 4 } & Poisson's ratio & PR & $0.1-0.48$ \\
\cline { 2 - 4 } & Overburden thickness (feet) & OB & $266-1184$ \\
\cline { 2 - 4 } & Cohesion (Lb/Inch $\left.{ }^{2}\right)$ & $\mathrm{C}$ & $580-5686$ \\
\cline { 2 - 4 } & Friction angle $($ degree) & FA & $20-60$ \\
\cline { 2 - 4 } & Tensile strength (lbs/in $\left.{ }^{2}\right)$ & TS & $29-1204$ \\
\hline Output & Optimal bolt length (feet) & OL & $0.033-$ \\
& & & 7.611 \\
\hline
\end{tabular}

\section{Statistical analysis}

Based on obtained results, linear and polynomial multiple variable regression analyses as well as dimensionless modeling and optimum modeling based on three other aforementioned models were undertaken to gain a prediction of the optimal bolt length based on independent input variables.

\subsection{Linear multiple variable regression analysis}

Using the SAS programme, the multiple variable regression analysis was carried out to estimate the minimal solid beam thickness (Luo 1999). According to this analysis, the value of the minimal beam thickness or the optimal length of a rock bolt in terms of six aforementioned input parameters could be calculated using Eq. 1 (Luo 1999):

$$
\begin{aligned}
& O L=\left(-1.26 \times 10^{-6}\right) \times(E)+0.7721 \times(P R)+ \\
& 0.0016 \times(O B)-0.0001 \times(C)-0.0023 \times(T S)- \\
& 0.0402 \times(F A)+5.0537 .
\end{aligned}
$$

For this model, the correlation coefficient $\mathrm{R}^{2}$ amounted to 0.7182 , which is somewhat low (Luo 1999). 


\subsection{Polynomial multiple variable regression analysis}

Polynomial analysis was carried out in order to improve the quality of estimation produced using the linear regression model. Nevertheless, it did not improve the prediction accuracy and the coefficient of correlation amounted to $68 \%$, which was even less than the value in case of the linear model (Luo 1999).

According to this modelling, the optimal bolt length in terms of inputs could be computed using Eq. 2 (Luo 1999):

$$
\begin{aligned}
& O L=30.32 \times(E)^{-0.02}+1.13 \times(P R)^{0.4}- \\
& 0.4126 \times(O B)^{-0.5}+6.87 \times(C)^{-0.05}+6.43 \times \\
& (T S)^{-0.27}+16.00 \times(F A)^{-0.2}-33.29
\end{aligned}
$$

\subsection{Dimensionless analysis}

Using a dimensionless analysis on independent input variables, Poisson's ratio becomes redundant in predicting the value of the optimal bolt length (Luo 1999), the value of which could be approximated using Eq. 3:

$$
O L=\frac{(O B)^{0.55}}{(E)^{0.04}(C)^{0.05}(T S)^{0.12}(F A)^{0.26}} .
$$

The value of the correlation coefficient for this analysis, just as for other previously mentioned statistical methods, was somewhat low as well and amounted to $70 \%$.

\subsection{Optimised statistical analysis}

As it was shown earlier, use of the above described statistical methods leads to an approximation of the optimal length of a rock bolt. Considering each of the results estimated by these analyses as separate independent variables and assigning a certain weight to each of them, the optimised model can be achieved through optimisation of the newly obtained mixed model (Luo 1999). below:

Thus, the optimised model would look as described

$$
\begin{aligned}
& O L_{\text {Optimized }}=0.3452 \times\left(O L_{\text {Linear }}\right)+0.3941 \times \\
& \left(O L_{\text {Polynomial }}\right)+0.2679 \times\left(0.2679_{\text {Dimensionless }}\right),
\end{aligned}
$$

where:

$\left(O L_{\text {Linear }}\right)$ : result of the linear model;

$\left(O L_{\text {Linear }}\right)$ : result of the polynomial model;

$\left(O L_{\text {Linear }}\right)$ : result of the dimensionless model.

Although this modeling improved the accuracy of prediction and increased the value of the correlation coefficient to $78 \%$ (Luo 1999), it has not reached the desired level to be acceptable. Subsequently, the need for a highly capable prediction tool that could be used to effectively and efficiently predict the value of the optimal bolt length became obvious.

\section{Artificial neural networks}

Artificial neural networks are a branch of the field known as Artificial Intelligence. These powerful tools were first- ly introduced by McCulloch and Pitts (1988) for calculation of logic functions. Yet, now they are broadly applied by a considerable number of researchers to model a target function based on available datasets (Khandelwal, Singh 2006; Young-Su, Byung-Tak 2006; Monjezi et al. 2010). In this method, a real experimental database is used to acquire relationships between involved parameters. The greater is the database of results, the more accurate is the prediction (Heshmati et al. 2009; Dikmen, Sonmez 2011; Khosrowshahi 2011).

The main role of artificial neural networks is to predict outputs based on inputs and the rules, which are learnt during the training phase.

In the attempt to prove that neural networks are able to recognise patterns, Rosenblatt (1958) built a perception network. One of the main benefits of neural networks in comparison to the statistical methods is the absence of a need to have prior knowledge about the nature of the problem, which is to be solved (Funahashi 1989). Besides, multilayer perception (MLP) networks are believed to be the best type of neural networks, which can be broadly used to predict any continuous function (Yasrebi, Emami 2008). This kind of network is composed of three types of layers: the input, the hidden and the output layer. In a MLP network, the number of layers depends on the type and complexity of a problem. However, at least one each - the input, the hidden and the output layers - are required (Yasrebi, Emami 2008). Each of these layers contains elements named neurons. These neurons are connected to each other; however, neurons in a layer cannot be connected to other neurons in the same layer. Subsequently, they can only be connected to neurons in other layers. Such nodes are connected by links. Each of these nodes has a specific weight vector, which is multiplied into the processed information. Transformation of the sum of the weighted input signals to each neuron is carried out by activation functions (Monjezi et al. 2010).

As the hidden layer uses nonlinear activation functions such as the logistic function, the model becomes genuinely nonlinear (Sarle 1994). A MLP can also have multiple inputs and outputs, as shown in Fig. 1.

In order to predict outputs, neural networks need to be trained using prepared datasets. Firstly, these datasets

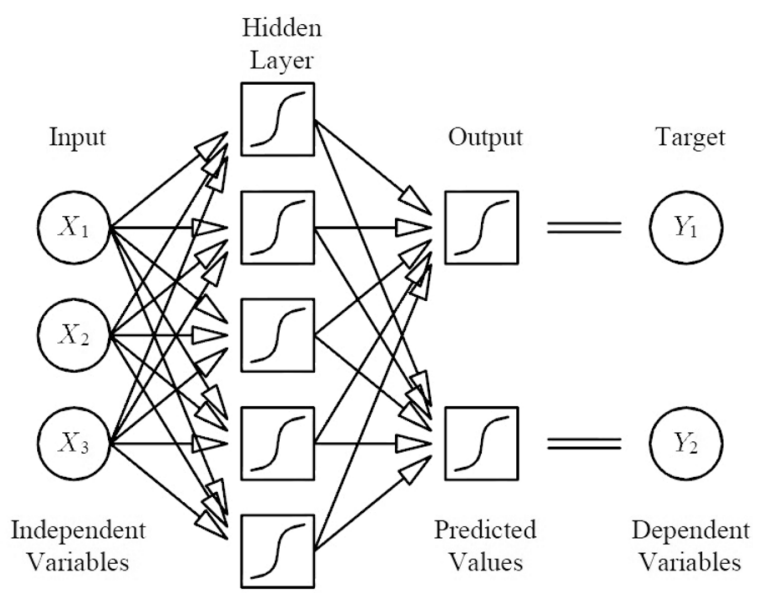

Fig. 1. Multilayer perceptron neural network (Sarle 1994) 
are fed into the network and then, by detecting the similarities, network gets trained; and while a new dataset is available, the network can predict the corresponding outputs based on what it has learnt during the training phase (Sarle 1994).

To create a true network, three following major components should be accurately defined and assigned, i.e. the transfer function, the learning law and the network architecture (Simpson 1990).

\subsection{Training the network}

One of the most and widely suggested training algorithms, which have been implemented by a variety of researchers for learning purposes, is backpropagation also known as BP (Neaupane, Adhikari 2006). This technique is composed of two passes: the forward pass and the backpropagation pass. In a forward pass, the network predicts the outputs assigning a preliminary value for connections between neurons. Then, in a backpropagation pass, the error - the computational difference between the calculated output and that of the target pattern, which is calculated in the forward pass - is backpropagated to update the weights. This procedure continues to reach the pre-defined threshold (Yang, Rosenbaum 2002).

It should be noted that in order to build the model, before the training phase begins, the contributing parameters - inputs and outputs - should be normalised on the scale of $0-1$. Eq. 5 can be used to normalise the data and make it dimensionless (Monjezi et al. 2010).

Scaled Value $=($ unscaled value $-\min$. value $) /$

(max. value - min. value).

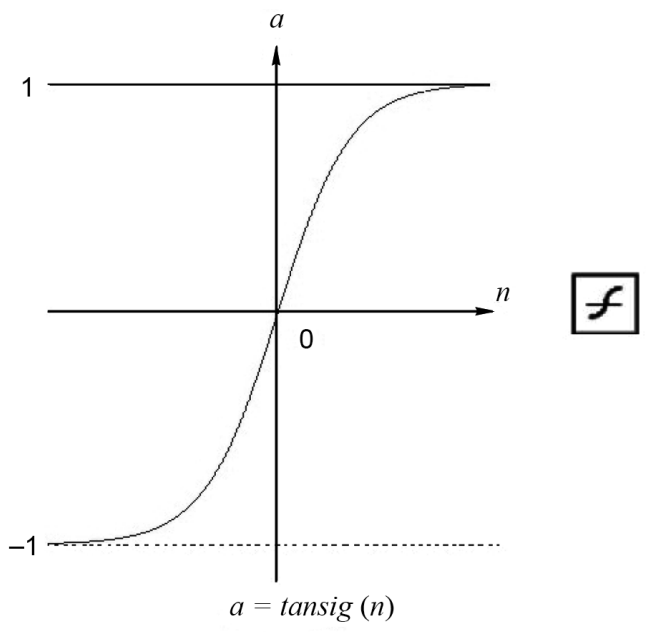

Fig. 2. Nonlinear TANSIG transfer function (Demuth et al. 1996)

Once data was normalised, $85 \%$ of the entire data were randomly chosen for training and cross-validation purposes. The remaining data was kept for testing of the built model. Besides, subsequent to a large number of trials on different networks, the nonlinear tangent sigmoid function TANSIG, which shows the minimal error, was considered as the transfer function. Fig. 2 shows the nonlinear
TANSIG transfer function. The TANSIG transfer function formula is presented in Eq. 6 (Demuth et al. 1996):

$$
f=\frac{e^{e_{x}}-e^{-e_{x}}}{e^{e_{x}}+e^{-e_{x}}}
$$

where $e_{x}$ is the weighted sum of the inputs for a processing unit (Demuth et al. 1996).

Other controlling problems, which should be avoided during the network training, include under-fitting and over-fitting. Over-fitting occurs as a result of using too many training epochs, which can be conducive to memorising the outputs. Under-fitting is a consequence of using insufficient number of training epochs, which results in model's inaccuracy (Maulenkamp, Grima 1999).

\subsection{Network architecture}

To gain the best model architecture, lots of 1-layer and 2-layer MLP networks were created. For all the built models, the value of root mean squared error, RMSE, and the mean absolute error, MAE, also, coefficient of correlation, $\mathrm{R}^{2}$, were calculated and compared. The applied formulas for calculating RMSE and MAE are presented as Eqs 7 and 8, respectively (Monjezi et al. 2010):

$$
\begin{gathered}
R M S E=\sqrt{\frac{\left(O_{i}-T_{i}\right)^{2}}{n} ;} \\
M A E=\left|T_{i}-O_{i}\right|,
\end{gathered}
$$

where $T_{i}$ and $O_{i}$ represent computed and predicted outputs, respectively. Also, $n$ is the number of data sets.

The values of RMSE and MAE as well as the correlation coefficient together with the slope of fitting line for different network architectures are given in Table 2.

As Table 2 suggests, the optimal model is the network with the architecture of 6-18-3-1, as it has the minimum RMSE and MAE as well as the maximum $\mathrm{R}^{2}$ with a slope of 1.0002 for the fitting line A.

To better describe the topology of the optimal network, its schematic architecture is demonstrated in Fig. 3.

Table 2. The value of RMSE, MAE, $\mathrm{R}^{2}$ and the slope of fitting line for different model's architecture

\begin{tabular}{c|c|c|c|c}
\hline Architecture & RMSE & MAE & $\mathrm{R}^{2}$ & $\mathrm{~A}$ \\
\hline $6-9-7-1$ & 0.2212 & 0.1597 & 0.520 & 0.1717 \\
\hline $6-3-8-1$ & 0.1892 & 0.1286 & 0.588 & 0.3288 \\
\hline $6-10-1$ & 0.1445 & 0.1111 & 0.510 & 0.3143 \\
\hline $6-5-1$ & 0.1499 & 0.1224 & 0.585 & 0.3418 \\
\hline $6-4-1$ & 0.1220 & 0.0885 & 0.552 & 0.4483 \\
\hline $6-9-1$ & 0.1209 & 0.1052 & 0.635 & 0.4233 \\
\hline $6-7-1$ & 0.1065 & 0.0975 & 0.426 & 0.4206 \\
\hline $6-12-3-1$ & 0.1061 & 0.0921 & 0.545 & 0.8932 \\
\hline $6-13-1$ & 0.0897 & 0.0784 & 0.734 & 0.9193 \\
\hline $6-4-13-1$ & 0.0872 & 0.0768 & 0.687 & 0.4185 \\
\hline $6-18-5-1$ & 0.0880 & 0.0659 & 0.893 & 0.4744 \\
\hline $6-4-9-1$ & 0.0866 & 0.0643 & 0.738 & 0.6019 \\
\hline $6-18-3-1$ & 0.0781 & 0.0682 & 0.926 & 1.0002 \\
\hline
\end{tabular}




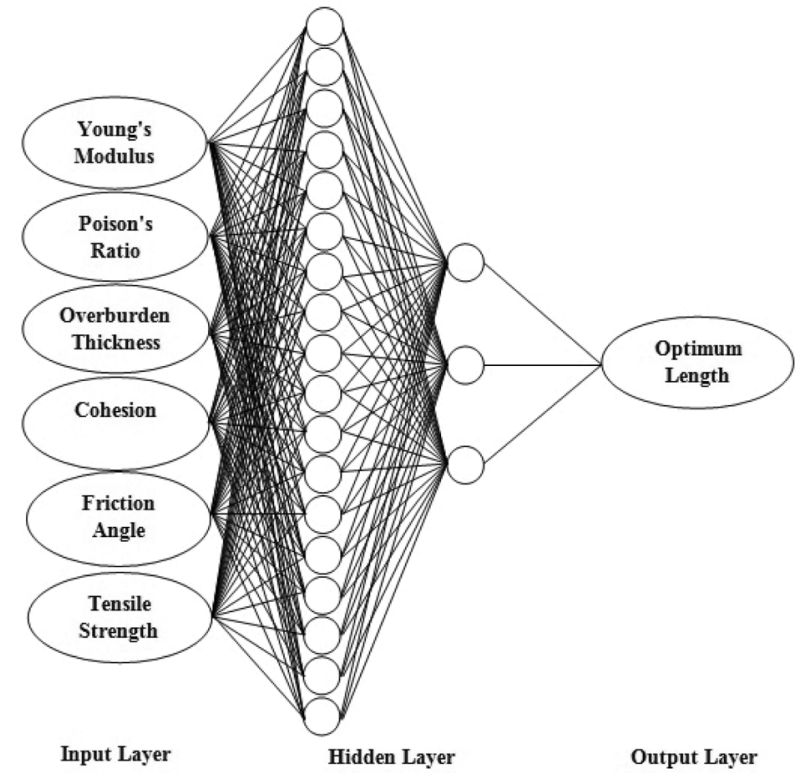

Fig. 3. Schematic architecture of the optimal network

\subsection{Model performance}

To evaluate the optimal model's performance for testing of data series, the normalised predicted values of the optimal bolt length versus its normalised computed values are depicted in Fig. 4.

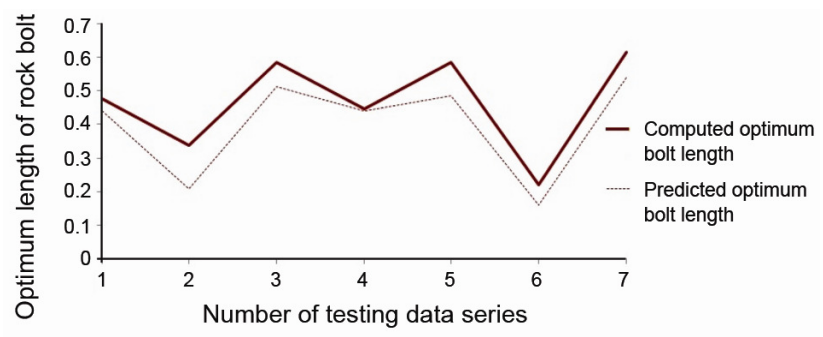

Fig. 4. The performance of the optimal model, 6-18-3-1

Also, as it is shown in Fig. 5, the value of $\mathrm{R}^{2}$ for the network with the topology of 6-18-3-1 is 0.926 , which proves the superiority of artificial neural network modelling over other aforementioned statistical methods in prediction of optimal bolt length.

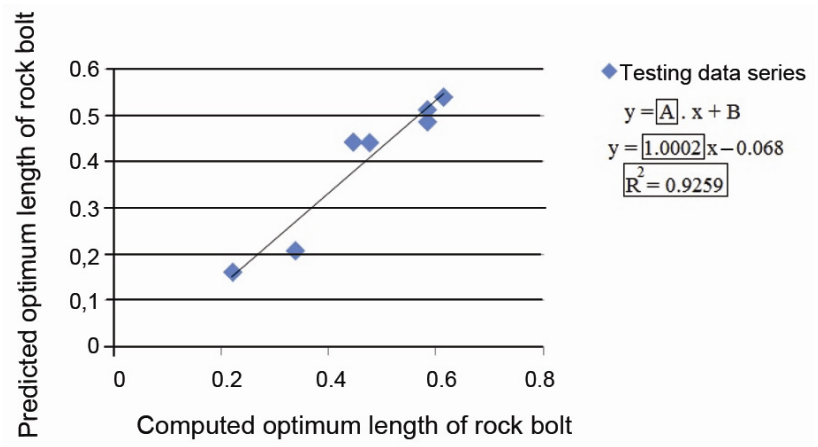

Fig. 5. Correlation between computed and predicted optimal bolt length for the optimal model, 6-18-3-1
In addition to high correlation with the computed optimal bolt length, which is confirmed by high value of the correlation coefficient, the values calculated for RMSE, 0.0781, and MAE, 0.0682, show high capability and performance of applied ANN model.

\section{Sensitivity analysis}

Knowledge of the most influencing parameters and the parameters with the least effect on the optimal rock bolt length considerably impacts the entire design procedure and makes it more cost-effective as well as timely.

Thus, the sensitivity analysis was made using the cosine amplitude method (CAM).

This method is used to achieve the express similarity relations between the input parameter and the goal function (Yang, Zhang 1997). In this method, each input parameter is expressed as one of $X$ array elements, as demonstrated in Eq. 9 (Khandelwal, Singh 2006):

$$
X=\left\{x_{1}, x_{2}, x_{3}, \ldots, x_{i}, \ldots x_{n}\right\},
$$

where each of its elements is a vector with the length of $m$ and is presented in Eq. 10:

$$
x_{i}=\left\{x_{i_{1}}, x_{i_{2}}, x_{i_{3}}, \ldots x_{i_{m}}\right\} .
$$

Then, the strength of the relationship between $x_{i}$ and $x_{j}$ can be calculated using Eq. 11 (Khandelwal, Singh 2006):

$$
r_{i j}=\sum_{m=1}^{k} x_{i_{m}} x_{j_{m}} / \sqrt{\sqrt{\sum_{m=1}^{k} x_{i_{m}}^{2} \sum_{m=1}^{k} x_{j_{k}}^{2}}} .
$$

Using these procedures, the most and the least sensitive parameters on the optimal rock bolt length were attained. The calculated strength of the relationship between input parameters and the optimal length of a rock bolt is shown in Fig. 6. According to the Fig. 6, the influence of Poisson's ratio, overburden thickness, cohesion and tensile strength on the optimal bolt length is approximately the same.

On the other hand, it was found that the friction angle has the least influence in determining the optimal length of a rock bolt.

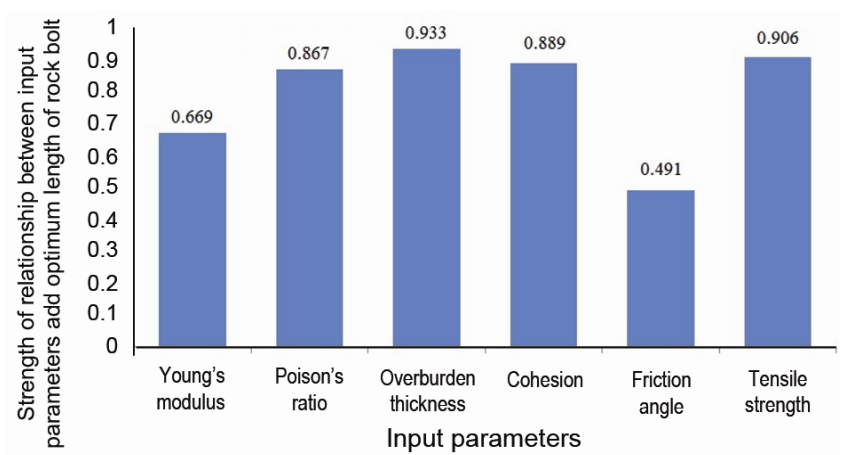

Fig. 6. Strength of the relationship between input parameters and the optimal length of a bolt 


\section{Conclusions}

An artificial neural network was introduced as a capable tool for prediction of the optimal length of a rock bolt.

It was discovered that the optimal model is a multilayer perception network with the architecture of 6-18-3-1.

High value of the correlation coefficient for the optimal created network, namely 0.926 , as well as acceptable values of RMSE, 0.0781, and MAE, 0.0681, proved the superiority of the artificial neural network modelling over the conventional statistical methods in prediction of the optimal bolt length. Besides, the 6-18-3-1 network trained by the feed forward backpropagation method was introduced as a capable tool in forecasting of the optimal length of a rock bolt.

Moreover, by means of sensitivity analysis based on the cosine amplitude method, the friction angle was reported as the least impacting parameter for the optimal bolt length. Besides, the influences of Poisson's ratio, overburden thickness, cohesion and tensile strength on the value of the optimal bolt length are almost the same.

However, the effect of the overburden thickness is slightly higher than others. Moreover, it plays a more important role in prediction of the optimal length of rock bolts.

\section{References}

Abu Kiefa, M. A. 1998. General regression neural networks for driven piles in cohesionless soils, Journal of Geotechnical and Geoenvironmental Engineering ASCE 124 (12): 1177-1185. http://dx.doi.org/10.1061/(ASCE)1090-0241 (1998)124:12(1177)

Amšiejus, J.; Dirgèlienè, N.; Norkus, A.; Žilionienė, D. 2009. Evaluation of soil shear strength parameters via triaxial testing by height versus diameter ratio of sample, The Baltic Journal of Road and Bridge Engineering 4(2): 55-60.

Baalousha, Y.; Celik, T. 2011. An integrated web-based data warehouse and artificial neural networks system for unit price analysis with inflation adjustment, Journal of Civil Engineering and Management 17(2): 157-167.

Barton, N.; Lien, R.; Lunde, J. 1974. Engineering classification of rock masses for the design of tunnel support, Journal of Rock Rock Mechanics Felsmechanik Mécanique des Roches [Mechanics and Rock Engineering] 6(4): 189236.

Belevičius, R.; Šešok, D. 2008. Global optimization of grillages using genetic algorithms, Mechanika 6: 38-44.

Belevičius, R.; Valentinavičius, S.; Michnevič, E. 2002. Multilevel optimization of grillages, Journal of Civil Engineering and Management 8(2): 98-103. http://dx.doi.org/10.1080/13923730.2002.10531259

Cai, Y.; Esaki, T.; Jiang, Y. 2004a. A rock bolt and rock mass interaction model, International Journal of Rock Mechanics and Mining Sciences 41(7): 1055-1067. http://dx.doi.org/10.1016/j.ijrmms.2004.04.005

Cai, Y.; Esaki, T.; Jiang, Y. 2004b. An analytical model to predict axial load in grouted rock bolt for soft rock tunnelling, Tunnelling and Underground Space Technology 19(6): 607-618.

http://dx.doi.org/10.1016/j.tust.2004.02.129

Chua, K. M.; Aimone, C.; Majtabai, N. 1992. A numerical study of the effectiveness of mechanical rock bolts in an underground opening excavated by blasting, in Proc. of the 33th U.S. Symposium on Rock Mechanics (USRMS), 3-5 June, 1992, Santa Fe, NM, American Rock Mechanics Association, Paper 92-0285. 10 p.

Demuth, H.; Beal, M.; Hagan, M. 1996. Neural network toolbox 5 user's guide. The Math Work, Inc., Natick. 852 p.

Dikmen, S. U.; Sonmez, M. 2011. An artificial neural networks model for the estimation of formwork labour, Journal of Civil Engineering and Management 17(3): 340-347. http://dx.doi.org/10.3846/13923730.2011.594154

Funahashi, K.-I. 1989. On the approximate realization of continuous mappings by neural networks, Neural Networks 2(3): 183-92.

http://dx.doi.org/10.1016/0893-6080(89)90003-8

Goh, A. T. C.; Wong, K. S.; Broms, B. B. 1995. Estimation of lateral wall movements in braced excavation using neural networks, Canadian Geotechnical Journal 32(6): 10591064. http://dx.doi.org/10.1139/t95-103

Hasanzadehshooiili, H.; Lakirouhani, A.; Medzvieckas, J. 2012. Evaluating elastic-plastic behaviour of rock materials using Hoek-Brown failure criterion, Journal of Civil Engineering and Management 18(3): 402-407. http://dx.doi.org/10.3846/13923730.2012.693535

Heshmati, A. A.; Alavi, A. H.; Keramati, M.; Gandomi, A. H. 2009. A radial basis function neural network approach for compressive strength prediction of stabilized soil, in Road Pavement Material Characterization and Rehabilitation: Selected Papers from the 2009 GeoHunan International Conference ASCE 191: 147-153.

Jankovski, V.; Atkočiūnas, J. 2010. SAOSYS toolbox as MATLAB implementation in the elastic-plastic analysis and optimal design of steel frame structures, Journal of Civil Engineering and Management 16(1): 103-121. http://dx.doi.org/10.3846/jcem.2010.10

Kelevišius, K.; Amšiejus, J.; Skuodis, Š. 2011. The influence of changing shaft friction of the pile to wave propagation, Engineering Structures and Technologies 3(2): 64-71. (in Lithuanian)

Khandelwal, M.; Singh, T. N. 2006. Evaluation of blast-induced ground vibration predictors, Soil Dynamics and Earthquake Engineering 27(2): 116-125.

http://dx.doi.org/10.1016/j.soildyn.2006.06.004

Khosrowshahi, F. 2011. Innovation in artificial neural network learning: Learn-On-Demand methodology, Automation in Construction 20(8): 1204-1210.

Kim, Y.; Gotoh, K.; Kim, K.; Toyosada, M. 2005. Optimum grillage structure design under a worst point load using real-coded micro-genetic algorithm, in Proc. of the 15th International Offshore and Polar Engineering Conference, 19-24 June, 2005, Seoul, Korea, 730-735.

Luo, L. 1999. A new rock bolt design criterion and knowledgebased expert system for stratified roof. PhD Dissertation, Virginia Polytechnic Institute and State University, Blacksburg, Virginia. $189 \mathrm{p}$.

Maity, D.; Saha, A. 2004. Damage assessment in structure from changes in static parameters using neural networks, Sadhana 29, Part 3: 315-327. http://dx.doi.org/10.1007/BF02703781

Malinowski, P.; Ziembicki, P. 2006. Analysis of district heating network monitoring by neural networks classification, Journal of Civil Engineering and Management 12(1): 21-28.

Malinowski, P.; Polarczyk, I.; Piotrowski, J. 2006. Neural model of residential building air infiltration process, Journal of Civil Engineering and Management 12(1): 83-88. 
Mang, H. A.; Jia, X.; Hoefinger, G. 2009. Hilltop buckling as the $\mathrm{A}$ and $\mathrm{O}$ in sensitivity analysis of the initial postbuckling behavior of elastic structures, Journal of Civil Engineering and Management 15(1): 35-46. http://dx.doi.org/10.3846/1392-3730.2009.15.35-46

Maulenkamp, F.; Grima, M. A. 1999. Application of neural networks for the prediction of the unconfined compressive strength (UCS) from Equotip hardness, International Journal of Rock Mechanics and Mining Sciences 36(1): 29-39. http://dx.doi.org/10.1016/S0148-9062(98)00173-9

McCulloch, W. S.; Pitts, W. 1988. A logical calculus of the ideas immanent in nervous activity, Bulletin of Mathematical Biophysics 5: 115-133.

http://dx.doi.org/10.1007/BF02478259

Monjezi, M.; Bahrami, A.; Varjani, A. Y. 2010. Simultaneous prediction of fragmentation and flyrock in blasting operation using artificial neural networks, International Journal of Rock Mechanics and Mining Sciences 47(3): 476-480. http://dx.doi.org/10.1016/j.ijrmms.2009.09.008

Neaupane, K. M.; Adhikari, N. R. 2006. Prediction of tunneling-induced ground movement with the multi-layer perceptron, Tunnelling and Underground Space Technology 21(2): 151-159.

http://dx.doi.org/10.1016/j.tust.2005.07.001

Peng, S. S.; Tang, D. H. Y. 1984. Roof bolting in underground mining: a state-of-the-art review, Geotechnical and Geological Engineering 2(1): 1-42.

Rosenblatt, F. 1958. The perceptron: a probabilistic model for information storage and organization in the brain, Psychological Review 65: 386-408.

http://dx.doi.org/10.1037/h0042519

Sarle, W. S. 1994. Neural networks and statistical models, in Proc. of the 19th Annual SAS Users Group International Conference, 10-13 April, 1994, Dallas, Texas. 13 p.

Schabowicz, K.; Hoła, J. 2008. Application of artificial neural networks in predicting earthmoving machinery effectiveness ratios, Archives of Civil and Mechanical Engineering 8(4): 73-84.

http://dx.doi.org/10.1016/S1644-9665(12)60123-X

Šešok, D.; Mockus, J.; Belevičius, R.; Kačeniauskas, A. 2010. Global optimization of grillages using simulated annealing and high performance computing, Journal of Civil Engineering and Management 16(1): 95-101.

http://dx.doi.org/10.3846/jcem.2010.09

Simpson, P. K. 1990. Artificial neural system: foundation, paradigms, applications and implementations. New York: Pergamon Press. 209 p.
Sivilevičius, H.; Daniūnas, A.; Zavadskas, E. K.; Turskis, Z.; Sušinskas, S. 2012. Experimental study on technological indicators of pile-columns at a construction site, Journal of Civil Engineering and Management 18(4): 512-518. http://dx.doi.org/10.3846/13923730.2012.709958

Stankus, J.; Guo, S. 1997. New Design Criteria for Roof Bolt System. in Proc. of the 16th Conference on Ground Control in Mining, 3-5 August, 1997, Morgantown, WV, 158-166.

Sušinskas, S.; Zavadskas, E. K.; Turskis, Z. 2011. Multiple criteria assessment of pile-columns alternatives, The Baltic Journal of Road and Bridge Engineering 6(3): 77-83.

Unal, E. 1983. Development of design guidelines and roofcontrol standards for coal-mine roofs. PhD Dissertation, Pennsylvania State University, University Park, PA. 380 p.

Weigel, W. 1943. Channel irons for roof control, Engineering and Mining Journal 144(5): 70-72.

Yang, Y.; Rosenbaum, M. S. 2002. The artificial neural network as a tool for assessing geotechnical properties, Geotechnical and Geological Engineering 20(2): 149-168. http://dx.doi.org/10.1023/A:1015066903985

Yang, Y.; Zhang, Q. 1997. A hierarchical analysis for rock engineering using artificial neural networks, Rock Mechanics and Rock Engineering 30(4): 207-222. http://dx.doi.org/10.1007/BF01045717

Yasrebi, S. S. H.; Emami, M. 2008. Application of Artificial Neural Networks (ANNs) in prediction and interpretation of pressuremeter test results, in Proc. of the 12th International Conference of International Association for Computer Methods and Advances in Geomechanics (IACMAG), 1-6 October, 2008, Goa, India, 1634-1638.

Young-Su, K.; Byung-Tak, K. 2006. Use of artificial neural networks in the prediction of liquefaction resistance of sands, Journal of Geotechnical and Geoenvironmental Engineering ASCE 132(11): 1502-1504. http://dx.doi.org/10.1061/(ASCE)1090-0241(2006)132: 11(1502)

Žaržojus, G.; Dundulis, K. 2010. Problems of correlation between Dynamic Probing Test (DPSH) and Cone Penetration Test (CPT) for cohesive soils of Lithuania, The Baltic Journal of Road and Bridge Engineering 5(2): 69-75. http://dx.doi.org/10.3846/bjrbe.2010.10

Zavadskas, E. K.; Turskis, Z.; Valutienė, T. 2010. Multiple criteria analysis of foundation instalment alternatives by applying Additive Ratio Assessment (ARAS) method, Archives of Civil and Mechanical Engineering 10(3): 123141. http://dx.doi.org/10.1016/S1644-9665(12)60141-1

Hadi HASANZADEHSHOOIILI. PhD student of the Dept of Civil Engineering, Faculty of Engineering, University of Guilan, Rasht, Guilan, Iran. He obtained his BSc in Mining Engineering from Urmia University in 2008 and his MSc in Geotechnical Engineering from University of Zanjan in 2011. His research interests include rock mechanics and geomechanics, geotechnical engineering (deep foundations), computational plasticity and mechanics, Hoek-Brown plasticity, numerical modeling, constitutive modeling of geo-materials and using ANNs in prediction of complicated civil engineering problems.

Ali LAKIROUHANI. PhD Assist. Prof. of the Dept of Civil Engineering, University of Zanjan, Zanjan, Iran. A graduate of Civil Engineering Faculty of Amirkabir University of Technology, Tehran, Iran (1998), MSc in geotechnical engineering (2000) and $\mathrm{PhD}$ in geotechnical engineering (2008). Research interests: hydraulic fracturing modeling (initiation of hydraulic fractures at a borehole to improve the interpretation of the in-situ stress from a hydraulic fracturing stress test.), tunnelling, rock slope stability.

Jurgis MEDZVIECKAS. Dr, Assoc. Prof. of the Geotechnical Dept of Vilnius Gediminas Technical University. A graduate of Civil Engineering Faculty of Vilnius Civil Engineering Institute (now - Vilnius Gediminas Technical University), Lithuania (1978). Dr in Structural Engineering (1989). Fields of research: foundation underpinning, relationship between ground and structures, estimation of soil mechanical properties. 